\title{
Finite element thermal analysis of the fusion welding of a P92 steel pipe
}

\author{
A. H. Yaghi, D. W. J. Tanner, T. H. Hyde, A. A. Becker, and W. Sun \\ Materials, Mechanics and Structures Research Division, Faculty of Engineering, University of Nottingham, \\ Nottingham NG7 2RD, UK \\ Correspondence to: A. H. Yaghi (anas.yaghi@nottingham.ac.uk)
}

Received: 22 November 2011 - Revised: 20 February 2012 - Accepted: 12 April 2012 - Published: 9 May 2012

Abstract. Fusion welding is common in steel pipeline construction in fossil-fuel power generation plants. Steel pipes in service carry steam at high temperature and pressure, undergoing creep during years of service; their integrity is critical for the safe operation of a plant. The high-grade martensitic P92 steel is suitable for plant pipes for its enhanced creep strength. P92 steel pipes are usually joined together with a similar weld metal. Martensitic pipes are sometimes joined to austenitic steel pipes using nickel based weld consumables. Welding involves severe thermal cycles, inducing residual stresses in the welded structure, which, without post weld heat treatment (PWHT), can be detrimental to the integrity of the pipes. Welding residual stresses can be numerically simulated by applying the finite element (FE) method in Abaqus. The simulation consists of a thermal analysis, determining the temperature history of the FE model, followed by a sequentially-coupled structural analysis, predicting residual stresses from the temperature history.

In this paper, the FE thermal analysis of the arc welding of a typical P92 pipe is presented. The two parts of the P92 steel pipe are joined together using a dissimilar material, made of Inconel weld consumables, producing a multi-pass butt weld from 36 circumferential weld beads. Following the generation of the FE model, the FE mesh is controlled using Model Change in Abaqus to activate the weld elements for each bead at a time corresponding to weld deposition. The thermal analysis is simulated by applying a distributed heat flux to the model, the accuracy of which is judged by considering the fusion zones in both the parent pipe as well as the deposited weld metal. For realistic fusion zones, the heat flux must be prescribed in the deposited weld pass and also the adjacent pipe elements. The FE thermal results are validated by comparing experimental temperatures measured by five thermocouples on the pipe outside surface with the FE temperature history at corresponding nodal points.

\section{Introduction}

The numerical simulation of the process of fusion welding of steel pipes in power generation plants has been the subject of research and publication for a few decades. Steel pipes are an essential component in fossil-fuel and other power plants, delivering steam at high temperature and pressure. The construction of the pipes requires joining them by applying fusion welding, involving intense thermal cycles, causing rapid heating and cooling of the welded metal. This induces residual stresses in the weld material and the heat affected zone (HAZ) of the pipes, which usually exceed the material yield stress at certain locations. The large magnitude of the welding-induced residual stresses can be detrimental to the mechanical performance of the welded components during service. This problem is usually overcome by the post-weld heat treatment (PWHT) of the welded pipes, which is costly and can be technically challenging; PWHT significantly reduces the magnitude of residual stresses but it cannot eliminate them. Therefore, the determination of residual stresses throughout the welded pipes can be valuable for deciding how to apply PWHT or indeed how to modify welding procedures to mitigate the ill-effects of residual stresses. 
The determination of residual stresses in welded pipes can be achieved by experimental procedures, such as techniques based on centre-hole drilling, deep-hole drilling, Xray diffraction and neutron diffraction, which are costly and difficult at times, and can involve destructive or semidestructive procedures, otherwise the revealed stress field is limited to the surface or near the surface (Yaghi et al., 2010). The experimentally-determined residual stress field is measured at specific locations only and the experimental methods involve averaging over an area, possibly missing out on sharp changes in the residual stress field which are typical of what is induced by the process of welding. The finite element (FE) numerical method, however, can provide residual stress predictions throughout the welded component, capturing the sharp peaks of the stress field, depending on the refinement of the generated FE mesh. The challenging part of providing accurate numerical results lies in acquiring a set of material properties which truly reflect the behaviour of the modelled material. If the required set of material properties for the numerical simulation is available and the generated FE mesh has sufficient refinement, the residual stress field due to welding can be accurately obtained throughout the FE model, making the FE method highly effective at predicting welding residual stresses.

The FE method comprises two parts: a thermal analysis, simulating the welding thermal cycles and delivering a temperature history throughout the welding process, and a sequentially-coupled structural analysis, processing the temperature history as input data and determining the developing thermal stresses and the residual stress field induced by the thermal cycles. Evidently, the accuracy of residual stresses is dependent on the accuracy of the temperature history determined by the thermal analysis. In this paper, the thermal analysis of an arc welded steel pipe, typically found in power generation plants, is presented. The pipe is made of P92 steel and is dissimilar in the sense that the weld metal is different from the two P92 parts being joined together. P92 steel pipes are usually joined together with a similar weld metal. Martensitic pipes are sometimes joined to austenitic steel pipes using nickel based weld consumables. In this study, the P92 steel pipe has been welded with a dissimilar weld metal for research purposes. The weld is a circumferential butt-weld consisting of 36 beads. The first bead or weld pass is made of Inconel 82 (IN82) and the remaining 35 beads or weld passes are made of Inconel 625 (IN625). P92, also known as NF616 in Japan, is a relatively newly-developed 9-12\% Cr ferritic steel that can be used in high temperature applications, such as in fossil-fuel and nuclear power stations as well as chemical plants. P92 is a modified form of its predecessor P91. Molybdenum, Mo, in P91 (9Cr1Mo) has been partially replaced by Tungsten, W, for P92 (9Cr2W). P92 has creep strength approximately $30 \%$ higher than the currently widely used steel P91 (Brózda, 2005), and it has proved suitable for piping and headers at temperatures up to around $625^{\circ} \mathrm{C}$ (Richardot et al., 2000). Hence, in modern super-critical steam power plants, P92 allows higher operating parameters and therefore higher efficiencies.

In general, an FE simulation of a welded pipe can be three-dimensional (3-D) or, when appropriate, can be two-dimensional (2-D) axisymmetric (Deng and Murakawa, 2006). A 3-D simulation is desirable when effects that cannot be otherwise modelled are revealed, such as stresses at welding starting and stopping locations. A 2-D axisymmetric simulation, however, can be more suitable, when such effects are to be ignored, and when the more uniform residual stress field is of interest. This is because a 2-D axisymmetric simulation can have a much finer FE mesh for the same computational processing time in comparison with a 3-D simulation of the same model, which can lead to significantly more accurate results for large models with numerous weld passes. 3-D models of welds with many passes can overcome the necessity of running prohibitively large analyses by employing techniques such as lumping of the weld passes together and keeping the FE mesh relatively coarse, which would reduce the accuracy of the results.

The reported thermal analysis is based on a 2-D axisymmetric model of the welded pipe with the FE mesh controlled using the facility named Model Change in Abaqus (ABAQUS User Manual, 2009). Model Change allows the weld material for each weld pass to become active during the numerical simulation at the time corresponding to the deposition of the pass. The heat delivered by the welding arc has been modelled by prescribing a uniformly distributed heat flux, which is a triangular function against time, corresponding to the approaching and then departing welding arc. The distributed heat flux has been applied to each weld pass when it is deposited and also to the surrounding pipe (parent) material in order to obtain the desired thermal contours in the FE model. In the FE thermal study, consideration has been given to fusion zones in the weld and parent material, peak temperature contours throughout the HAZ and the temperature history at locations corresponding to a set of attached thermocouples. The actual welded pipe had five thermocouples attached at different locations, making it possible to validate the temperature history determined by the reported FE thermal analysis.

\section{Dissimilar welded pipe}

The FE thermal analysis has been conducted to model the thermal behaviour of a welded steel pipe. Prior to welding, the P92 pipe was cut into two halves and the ends prepared for joining, a photograph of which is shown in Fig. 1. The two halves were axisymmetrically aligned and held in large metal vices and then welded together using 36 weld beads (or passes) of dissimilar weld materials. The right-hand side was released after the third weld pass had been completed, and the left-hand side remained fixed throughout the process of welding - please see Fig. 2. 
Table 1. Chemical composition of the pipe and weld materials.

\begin{tabular}{lccccccccccccccc}
\hline & $\mathrm{Fe}$ & $\mathrm{C}$ & $\mathrm{Mn}$ & $\mathrm{P}$ & $\mathrm{S}$ & $\mathrm{Si}$ & $\mathrm{Cr}$ & $\mathrm{W}$ & $\mathrm{Mo}$ & $\mathrm{V}$ & $\mathrm{Nb}$ & $\mathrm{N}$ & $\mathrm{B}$ & $\mathrm{Al}$ & $\mathrm{Ni}$ \\
\hline P92 & Bal & 0.10 & 0.45 & 0.015 & 0.002 & 0.45 & 8.62 & 1.86 & 0.33 & 0.21 & 0.076 & 0.047 & 0.003 & 0.019 & 0.27 \\
IN625 & 1.48 & 0.03 & 0.76 & 0.005 & 0.005 & 0.33 & 21.9 & - & 8.67 & - & 3.340 & - & - & - & Bal \\
IN82 & 0.80 & 0.01 & 3.00 & - & - & 0.10 & 20.0 & - & - & - & 2.700 & - & - & - & Bal \\
\hline
\end{tabular}

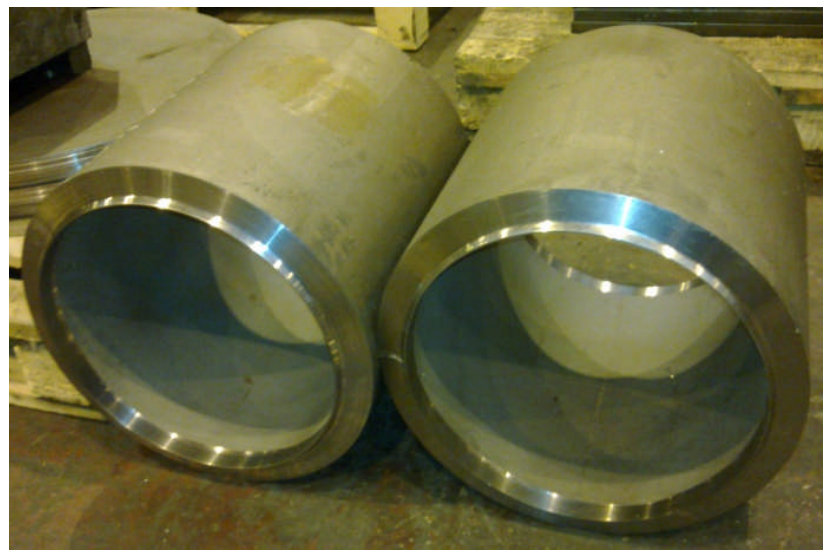

Figure 1. P92 pipe before welding.

\subsection{Pipe geometry, weld details and material specifications}

The geometry and dimensions of the welded P92 pipe, as well as the welding sequence, are shown in Fig. 3. The welded pipe has an outside diameter of $355 \mathrm{~mm}$ and a total length of $700 \mathrm{~mm}$. The first weld pass was deposited by tungsten inert gas (TIG) welding using the nickel based weld material Inconel 82 (IN82), having the manufacturer's brand name UTP A068HH, with a rod diameter of $2.4 \mathrm{~mm}$, during which argon gas was used to shield the weld from atmospheric gases. Weld passes 2 to 36 were deposited by manual metal arc (MMA) welding using the nickel based weld material Inconel 625 (IN625), having the manufacturer's brand name NIMROD $625 \mathrm{KS}$, with the filler rod for weld passes 2 and 3 having a diameter of $3.2 \mathrm{~mm}$ and the remaining passes having a diameter of $4.0 \mathrm{~mm}$. The chemical compositions for the parent and weld materials are shown in Table 1. The material properties are discussed in Sect. 3.2.

\subsection{Thermocouples and weld procedure}

The temperature of the pipe was monitored during welding by attaching five thermocouples to the surface of the pipe and recording the temperatures with a chart plotter throughout the welding process. The thermocouples measured the surface temperature at five different locations with varying distance from the weld centre line (WCL) and also at different angular positions around the pipe circumference. Since the FE analysis is axisymmetric, the angular position of the

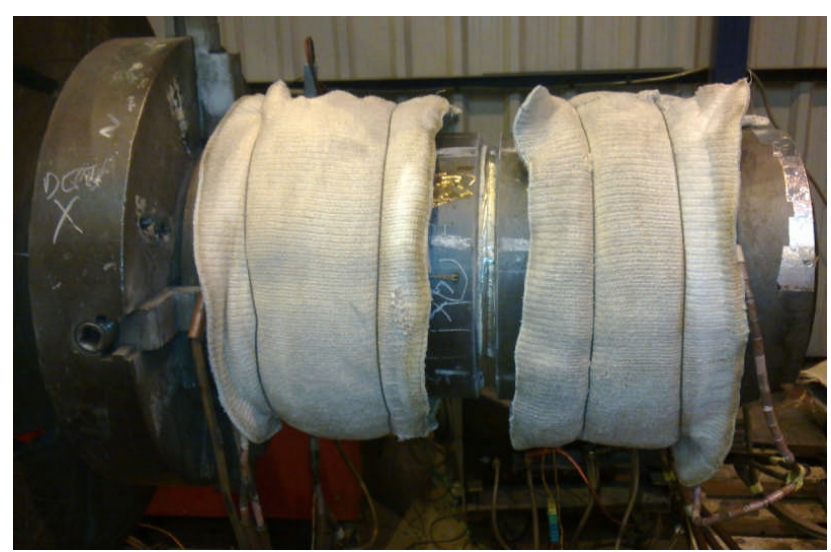

Figure 2. P92 pipe during welding.

thermocouples around the circumference is irrelevant to the reported study. The fact that the angular position varies for the thermocouples, however, is relevant in explaining some of the scatter noticed in the temperature results as well as some of the discrepancies observed between the experimentally measured and the FE determined temperatures, as will be discussed later in the paper. Thermocouples 1 and 2 (TC1 and TC2) are closest to the weld and are located on the lefthand pipe section, both at an axial distance of $32.4 \mathrm{~mm}$ from the WCL. The other thermocouples, TC3, TC4 and TC5, are located on the right-hand pipe section at axial distances of $35.0 \mathrm{~mm}, 40.5 \mathrm{~mm}$ and $70.3 \mathrm{~mm}$ from the WCL, respectively. All the distances were measured after depositing the third weld pass and before the rest of the passes were deposited, i.e. before any significant deformation took place. It is worth noting that the distances relating to the thermocouples are accurate to within $\pm 0.5 \mathrm{~mm}$; they are, however, quoted here to the stated precision to correspond to the matching nodal positions in the FE mesh, where temperature comparisons are made.

The thermocouples were used to monitor the temperature of the pipe to maintain the required preheat and interpass temperature, necessary in the case of P92 steel for a welding procedure which would likely be free from the risk of micro or macro-cracking during welding or just after, as the pipe cooled to room temperature. The temperature history obtained from the thermocouples has also been used to validate the thermal behaviour determined by the FE simulation. The pipe was heated by an electric blanket on both sides as can be 


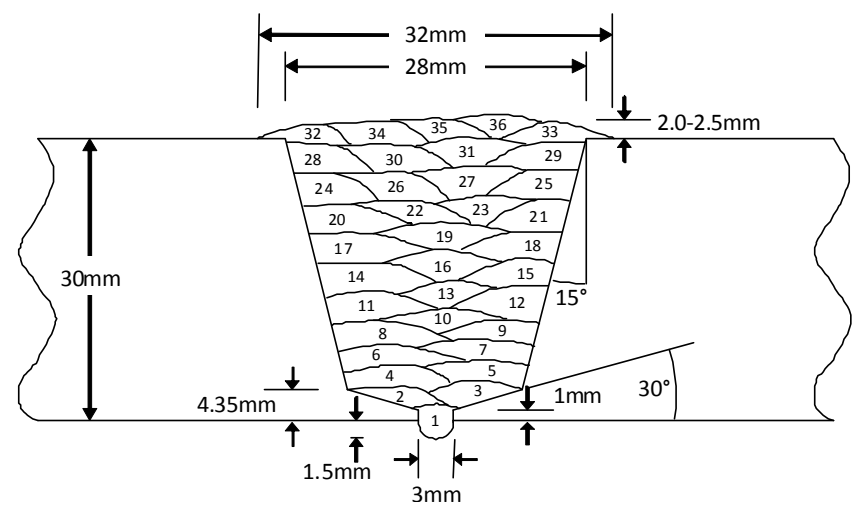

Figure 3. Sketch of weld bead sequence showing overall weld dimensions.

seen in Fig. 2. Although the blanket would go on and off and would reach relatively high temperatures when switched on, the temperatures at the weld region and the HAZ were relatively steady, and therefore the FE modelling of the blanket effect was achieved by prescribing a sink temperature at the surface where the blanket was in contact with the pipe. The sink temperature was varied from one weld pass to the other (from $105^{\circ} \mathrm{C}$ for Pass 1 to $251^{\circ} \mathrm{C}$ for Pass 26), during the FE simulation, to emulate the experimentally measured temperatures during the interpass periods. During the actual welding of the pipe, as recommended by literature, it was aimed to keep the preheat and interpass temperatures for the TIG welding of the first pass between $100^{\circ} \mathrm{C}$ and $150^{\circ} \mathrm{C}$ (Holloway et al., 2008) and for the MMA welding of all the other passes between $200^{\circ} \mathrm{C}$ and $250^{\circ} \mathrm{C}$ (Richardot et al., 2000).

\section{FE thermal analysis}

The FE thermal analysis reported in this paper is part of a more complete FE simulation intended by the authors to determine welding residual stresses for the dissimilar welded P92 pipe. The FE thermal analysis, which forms the first part of the simulation, is reported here, whereas the sequentially coupled structural analysis, which forms the second part of the simulation, is to be reported in a future publication. The type of simulation adopted by the authors is described as solid-mechanical, modelling the heat flux delivered to the pipe by the heat source and allowing for the thermo-physical behaviour, such as conductivity, and then translating the thermal effects into structural mechanical effects, such as volume expansions and plasticity, without allowing for any fluid effects of the molten regions. The solid mechanics approach is justified in ignoring the fluid effects, since stresses become significant only when the material has solidified and is relatively cool. When the material is molten or close to being molten, it is soft enough not to sustain any significant stresses. As long as the mechanical properties used in

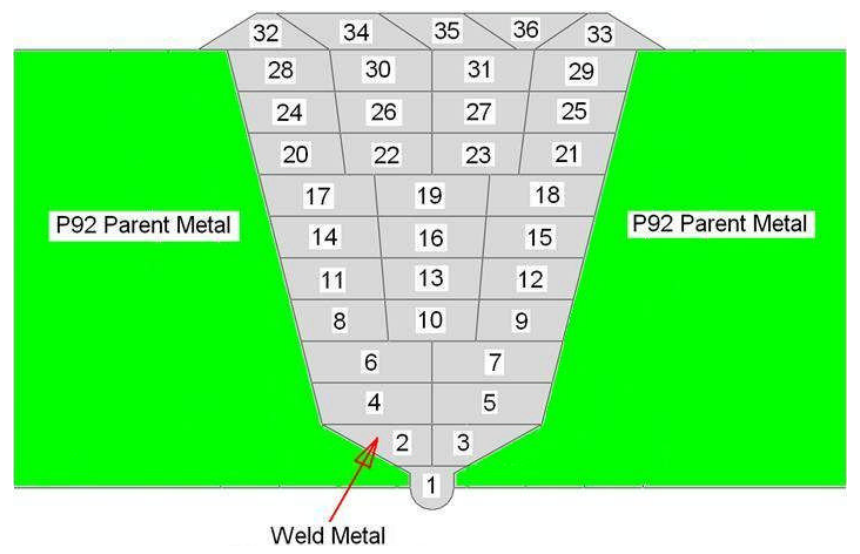

Figure 4. Weld pass sequence in the FE model.

the simulation represent the actual behaviour of the material, fluid effects do not have to be taken into consideration.

\subsection{FE model of the welded pipe}

The FE simulation of the fusion welding of the dissimilar welded P92 pipe starts with generating an FE model by firstly creating an FE mesh. The commercial package used for this purpose and indeed for performing the complete FE thermal analysis, reported in this paper, is Abaqus (ABAQUS User Manual, 2009). A complete FE mesh has been generated from the start, which includes the pipe and the weld region.

The weld pass sequence in the FE model is identical to that in the actual weld, as shown in Fig. 4. The shape of the weld passes in the FE model does not have to accurately match the actual shape of the weld beads to produce representative and realistic thermal contours (Yaghi et al., 2010). Although the shapes of the FE passes are rather square compared to the actual weld, the resulting thermal contours emerge rounded and realistic. Nonetheless, it is believed that the final layer of weld passes has the most significant effect on residual stresses, and therefore an attempt has been made to make the final layer closer in shape to the actual weld beads. The shape of the final layer of beads can easily be adjusted without unduly complicating the FE model, which is not the case for the other beads. The actual FE mesh which has been generated for the model is shown in Figs. 5 and 6. It can be seen in Fig. 5 that the mesh is refined in the weld region and HAZ and that it becomes gradually coarser as it moves away from the weld, as shown in Fig. 6. The complete 2-D axisymmetric FE mesh comprises 9022 nodes and 2919 elements. The element type used throughout the FE model is an eight-node continuum solid quadratic axisymmetric diffusive heat transfer quadrilateral, given the name DCAX8 in Abaqus.

The elements in the FE mesh forming each weld pass are assigned a group name so that each pass can be deposited independently during the simulation. At the inception of the simulation, the elements of all the weld passes 


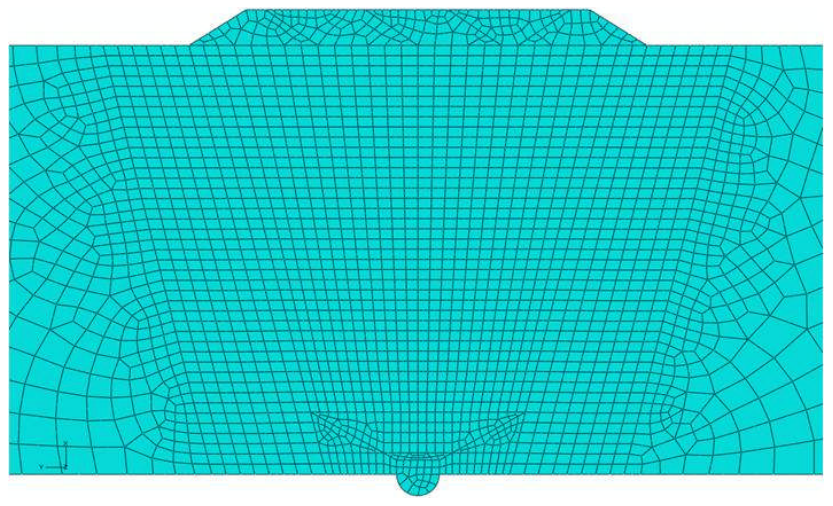

Figure 5. FE mesh showing the weld, HAZ and part of the pipe.

Figure 6. Complete 2-D axisymmetric FE mesh.

are made to become inactive, rendering them thermally dormant, while still keeping all the elements of the mesh attached together. This is achieved in Abaqus by using the command "Model Change, Type = Element, Remove" at the beginning of the first step in the input file of the thermal analysis. Each weld pass is deposited in the corresponding step in the thermal analysis by using the command "Model Change, Type = Element, Add", which reactivates the corresponding elements in the FE mesh.

The requirement of the FE model to exchange heat, at its surface, with the surrounding environment is facilitated using the option "sfilm" in the input file. A surface film or "sfilm" is generated by selecting the outside surface of relevant elements which are expected to exchange heat with the surroundings by convection and radiation or due to direct contact with a solid material as in the case of the electric blanket. The surface film is specified and the film properties are assigned values to allow appropriate amount of heat to be exchanged at the surface. The temperature of the environment surrounding the model is specified by prescribing a constant sink temperature of $20^{\circ} \mathrm{C}$ at the relevant surfaces. Therefore, by specifying sets of surface films and film properties, the FE model can exchange heat with the surroundings, simulating the heat flow between the surface of the model and the environment, whether the surface belongs to the weld or pipe, and also between the pipe and the electric blanket. The surface film is made to follow the evolution of the outside surface as the deposition of each weld pass is simulated.

\subsection{Material properties}

The material property data required for the FE thermal analysis have been obtained for three different materials, namely, P92 steel, Inconel 82 (IN82) and Inconel 625 (IN625). Some of the data are available in literature, but some have been de-

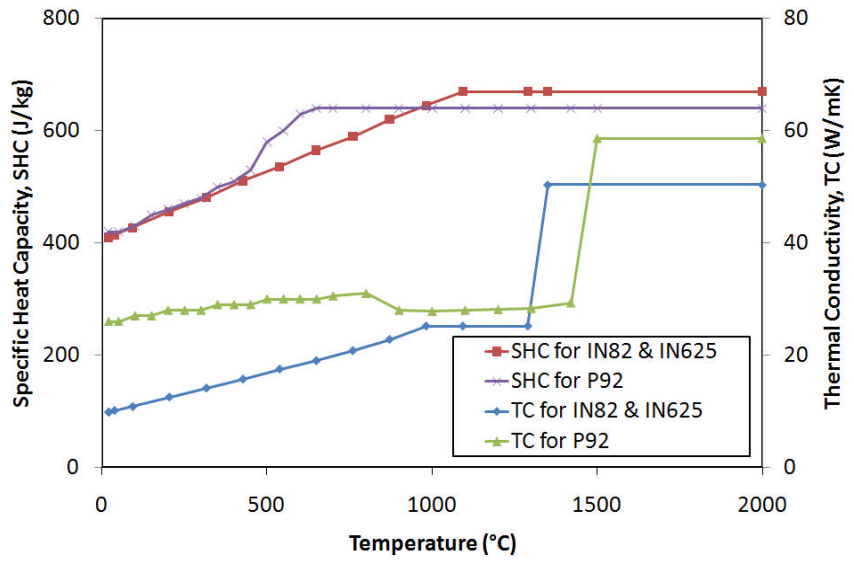

Figure 7. Thermal conductivity and specific heat capacity in the FE model.

rived either by extrapolation to higher temperatures or by referring to other similar materials with known material property data. This approach has been adopted, since parametric analyses by the authors of welding residual stresses for different materials have indicated that welding residual stresses in general are mostly sensitive to the value of yield stress as well as that of the coefficient of linear thermal expansion (which are part of the FE structural analysis); they are significantly less sensitive to changes in thermal properties; moreover, heat fluxes would have to be adjusted to obtain realistic molten zones, which would in turn compensate for inaccuracies in the thermal properties. It has also been possible to calculate melting temperatures from thermodynamic software packages. The material properties that need to be specified in the thermal analysis are the thermal conductivity, density, specific heat capacity, latent heat capacity, solidus and liquidus temperatures and heat transfer coefficients.

The FE model uses the thermal conductivity of P91 steel (Yaghi et al., 2010). The specific heat capacity of P92 steel has been obtained from literature (Richardot et al., 2000) from room temperature up to $650^{\circ} \mathrm{C}$, above which it has been assumed to remain unchanged. Both material properties are shown in Fig. 7. The solidus and liquidus temperatures for P92 steel have been calculated as $1420^{\circ} \mathrm{C}$ and $1500^{\circ} \mathrm{C}$ by using MTDATA software developed at the National Physical Laboratory (NPL) in the UK and they have been corroborated by the same values published for P91 steel (Yaghi et al., 2010). The density for $P 92$ steel is specified in literature (Richardot et al., 2000) as $7850 \mathrm{~kg} \mathrm{~m}^{-3}$. The latent heat capacity for P92 steel has been assumed to be the same as that for P91 steel, specified as $260 \mathrm{~kJ} \mathrm{~kg}^{-1}$ (Yaghi et al., 2010).

The thermal conductivity and specific heat capacity of IN625 are provided in literature (Special Metals, 2006) for temperatures up to $982^{\circ} \mathrm{C}$ and $1093{ }^{\circ} \mathrm{C}$, respectively. The same values have been assumed for the weld material NIMROD $625 \mathrm{KS}$ for the given temperature range, above which the two thermal properties are assumed to remain constant 
up to the melting point. As the material goes from the solidus to the liquidus temperature, the thermal conductivity is doubled in magnitude to compensate for the stirring effects in the molten state (Brickstad and Josefson, 1998). The same thermal conductivity and specific heat capacity have been assumed for the weld material UTP A068HH used for the first pass due to the lack of data for IN82. It is worth noting that the effect of the first weld pass on residual stresses near the outside surface of the pipe, where most interest lies for such wall thickness, is expected to be negligible. The thermal conductivity and specific heat capacity for the weld materials are shown in Fig. 7. The density for IN625 is given as $8440 \mathrm{~kg} \mathrm{~m}^{-3}$ (Special Metals, 2006). This value has been assumed for both weld materials. The latent heat capacity for pure nickel is listed as $297 \mathrm{~kJ} \mathrm{~kg}^{-1}$ (The Engineering ToolBox, 2011). Therefore, an approximate and intermediate value between those of P92 steel and pure nickel of $280 \mathrm{~kJ} \mathrm{~kg}^{-1}$ has been assumed for the weld materials. The solidus and liquidus temperatures for UTP A068HH have been calculated to be $1301{ }^{\circ} \mathrm{C}$ and $1368^{\circ} \mathrm{C}$ and for NIMROD $625 \mathrm{KS}$ to be $1250^{\circ} \mathrm{C}$ and $1345^{\circ} \mathrm{C}$, respectively, using the software ThermoCalc Classic Version S (TCC), developed by the Foundation of Computational Thermodynamics in Stockholm of Sweden, and utilising Thermotech Nickels Database Version 7 (TTNi7) (Saunders et al., 1996).

Heat losses at the surface of the pipe have been modelled by prescribing appropriate values for the coefficient of heat transfer under the Abaqus command Film Property. Heat loss coefficients for P92 steel and also the Inconel weld material have been assumed to be the same as those for P91 steel, given in literature (Yaghi et al., 2005) to be $0.0668 T$ $\left(\mathrm{W} \mathrm{m}^{-2} \mathrm{~K}\right.$ ) when the temperature $T$ is below $500^{\circ} \mathrm{C}$ and $0.231 T-82.1\left(\mathrm{~W} \mathrm{~m}^{-2} \mathrm{~K}\right)$ when $T$ is above $500^{\circ} \mathrm{C}$. A similar approach has been adopted to model the effect of the electric blanket on the pipe. Recognising that the blanket would fluctuate in temperature substantially and would be switching on and off to control the interpass temperature during welding, the modelling has been simplified to having the blanket at a constant temperature during the deposition of any one weld pass, prescribing a very high value to the coefficient of heat transfer at the surface with which the blanket has contact, and controlling the sink temperature at that surface (between $105^{\circ} \mathrm{C}$ for Pass 1 and $251{ }^{\circ} \mathrm{C}$ for Pass 26) to obtain the desired temperature history at the five thermocouples. The value prescribed for the coefficient of heat transfer for this purpose is $200 T\left(\mathrm{~W} \mathrm{~m}^{-2} \mathrm{~K}\right)$, where $T$ is the temperature of the pipe.

\subsection{Heat fluxes and fusion zones in the FE model}

The main part of the thermal analysis is to model the effect of the heat source on the pipe during fusion welding, i.e. the heat delivered by the welding arc into the weld and surrounding material. This has been covered in detail for similar welded pipes in a previous publication (Yaghi et al., 2005).
The modelling method, however, needs to be modified for the thermal analysis of a dissimilar welded pipe, as is the case here.

In general, the heat effect of the welding arc on a pipe can be modelled by prescribing a uniformly distributed heat flux (Dflux in Abaqus) for each of the weld passes as they are deposited. In the reported work, the flux is assumed to follow a triangular function (Yaghi et al., 2005), which starts from zero and rises linearly to reach a peak at half time, to signify the approach of the weld arc, and then it decreases linearly back to zero at full time, to signify the departure of the arc. The welding speed was determined to be around $50 \mathrm{~mm} \mathrm{~min}^{-1}$ for the first pass and ranged between 152 and $207 \mathrm{~mm} \mathrm{~min}^{-1}$ for the remaining passes. The welding current ranged between 90 and $130 \mathrm{~A}$, and the DC voltage ranged between 9 and 10 for the first pass and between 24.3 and $26.5 \mathrm{~V}$ for passes 2 to 36 . The heat flux in the FE model lasted for $10.7 \mathrm{~s}$ for the first pass, $5.9 \mathrm{~s}$ for each of the second and third passes, and between $6.6 \mathrm{~s}$ and $7.6 \mathrm{~s}$ for each of the remaining passes. The method of deriving the heat flux from the welding parameters for a 2-D axisymmetric FE model has been described in detail elsewhere (Yaghi et al., 2005). When the flux for each pass had been estimated in the reported study, the magnitudes for the 36 passes were specified in a tabular form in the Abaqus input file. The tabular form comes under the Abaqus command Amplitude. Initially, the same conventional method was followed of prescribing the flux for each pass at the elements forming the weld pass material. If the welded pipe were not dissimilar, that would usually produce the expected thermal contours and fusion zones. In the reported study, however, the welded pipe is dissimilar, i.e. the weld material is different from that of the pipe; also, the melting temperatures for the materials are substantially different. This caused the fusion zones to be unrealistic when the initial analysis was conducted; fusion zones in the weld developed as expected, but the pipe material, having a higher melting temperature range, remained solid. An example of an unrealistic fusion zone is shown in Fig. 8 for weld pass 14. The figure shows fusion into the pre-deposited weld material, surrounding the current pass, to a depth of $2.2 \mathrm{~mm}$ and no fusion at all in the pipe (parent) material.

The conventional method has been modified by prescribing the heat flux for each weld pass in the elements forming the weld pass and also in the pipe material surrounding the same pass. This is consistent with the actual welding practice, as the arc delivers heat to the pipe material as well as the weld. This modification has resulted in obtaining realistic fusion zones. Fusion into the weld material surrounding the current pass is expected to be typically between 1.5 and $2.5 \mathrm{~mm}$ and into the pipe material to be between 1.0 and $2.0 \mathrm{~mm}$. If the fusion zone for any weld pass is not as expected, the heat flux can be adjusted until realistic results are obtained. The heat flux in the input file can be adjusted either by modifying the numbers in the Amplitude table or by including a modifying factor referred to as the Reference Flux 


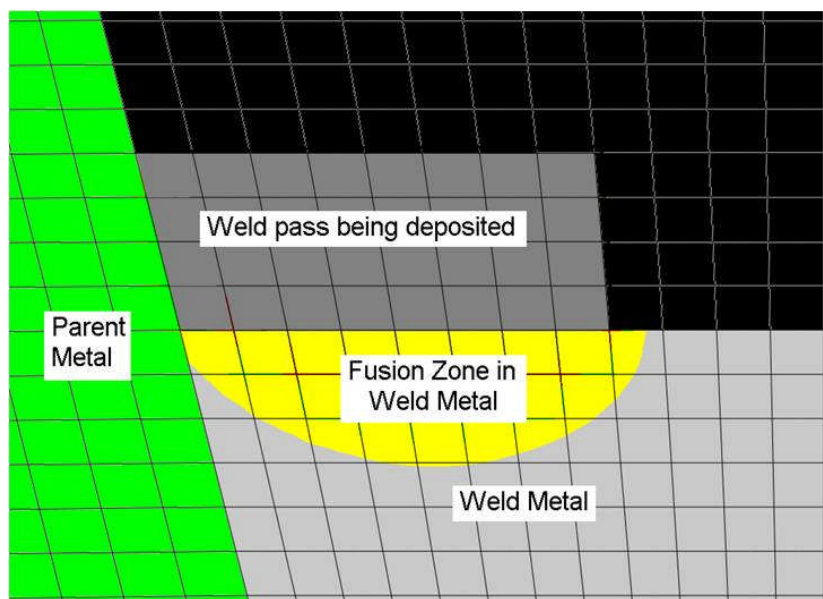

Figure 8. Fusion zone when heat flux is applied only to weld elements.

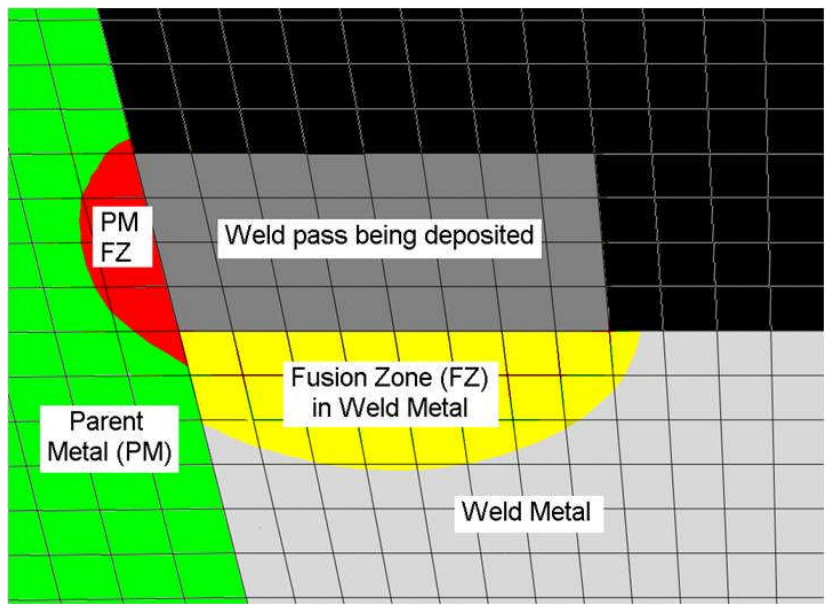

Figure 9. Fusion zones (FZ) when heat flux is applied to pipe and weld elements.

Magnitude, the value of which comes under the Abaqus command Dflux, within the corresponding step in the input file. An example of a realistic fusion zone is shown in Fig. 9 for weld pass 14 . The figure shows a fusion of $2.2 \mathrm{~mm}$ into the weld material and $1.2 \mathrm{~mm}$ into the pipe (parent) material. It also shows that the weld pass causes melting throughout the surface it comes into contact with, otherwise the quality of the weld would be compromised. The average Dflux for the whole welding process is $9.15 \mathrm{GW} \mathrm{m}^{-3}$ and the average time span is $7.2 \mathrm{~s}$.

\subsection{Comparison of FE temperatures and thermocouple measurements}

The FE thermal results have been validated by comparing them to the temperature history measured by five thermocouples (TC1, TC2, .., TC5). The temperature history at the locations of the thermocouples predicted by the FE ther-

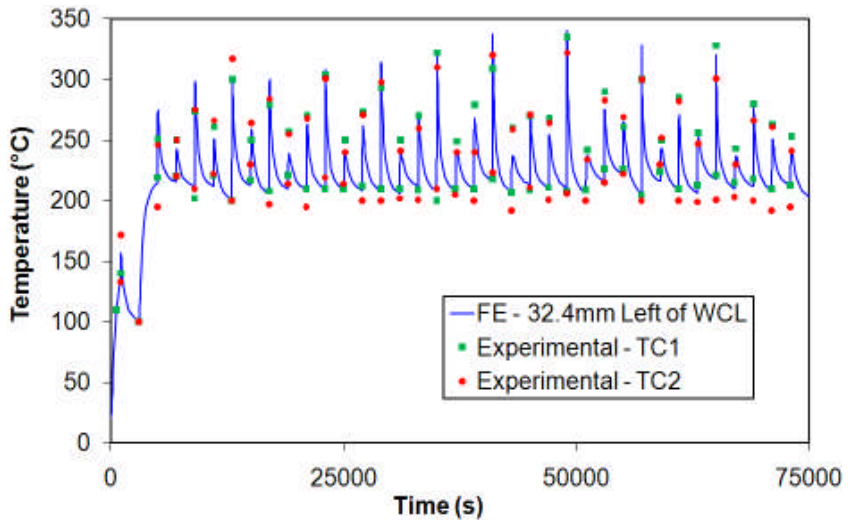

Figure 10. Temperature measurements by TC1 and TC2 and FE temperature history.

mal analysis can be made to vary significantly (tens of degrees) by altering the magnitude of the heat fluxes and the corresponding time spans over which the fluxes last. The heat fluxes and the time spans have to be changed together so as to keep the fusion zones unchanged. This way, the FE temperature history at the thermocouple locations can be changed without disrupting the fusion zones which are consistent with realistic expectations. The final set of heat fluxes and time spans have been reached and their average values are reported in the previous subsection.

Comparisons between the FE predicted temperatures and the measured temperatures by the thermocouples are depicted in Figs. 10 to 14. Figure 10 shows measured temperatures by TC 1 and TC 2 and corresponding FE temperatures at $32.4 \mathrm{~mm}$ to the left-hand side of the WCL. Although both thermocouples are attached at an equal distance from the WCL (at different angular locations around the pipe), they exhibit a slightly different temperature history. This will evidently be missed out in a 2-D axisymmetric FE analysis due to its 2-D nature. Also, this provides a justification for the discrepancies between the FE results and the experimentally measured temperatures, with the discrepancies varying from one pass to another depending on starting and stopping positions relative to the measurement locations, bearing in mind that for each weld pass (once around the circumference) there were six sets of starting and stopping points. The results from TC1 and TC2 are averaged and compared again to the FE temperatures at $32.4 \mathrm{~mm}$ to the left-hand side of the WCL in Fig. 11. Figures 12, 13 and 14 compare the results from TC3, TC4 and TC5, respectively, with the FE temperatures at the right-hand side of the WCL at corresponding axial distances of $35.0 \mathrm{~mm}, 40.5 \mathrm{~mm}$ and $70.3 \mathrm{~mm}$ from the WCL, respectively. The five figures each depict the thermal cycles corresponding to the 36 passes. The variety in the full experimental time span between depositing any two weld passes, observed from the thermocouple chart plotter, is not shown, since it does not add value to the presented information. It is 


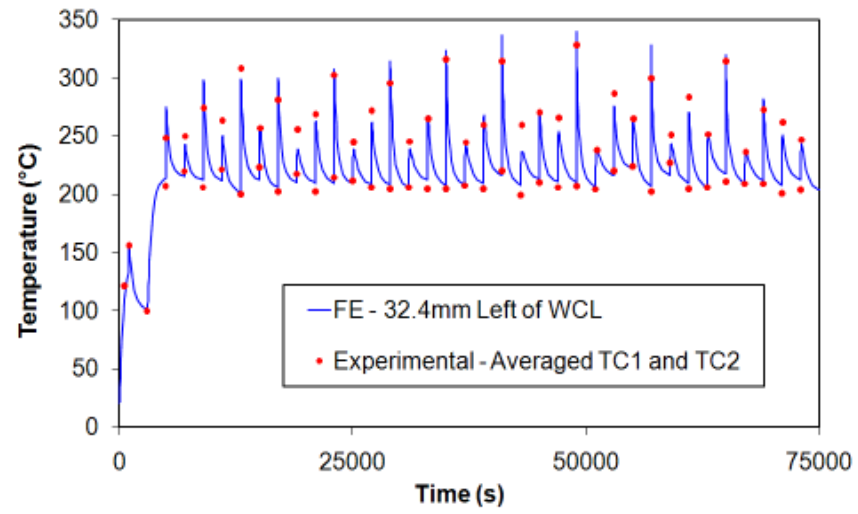

Figure 11. Temperature measurements by TC1 and TC2 and FE temperature history.

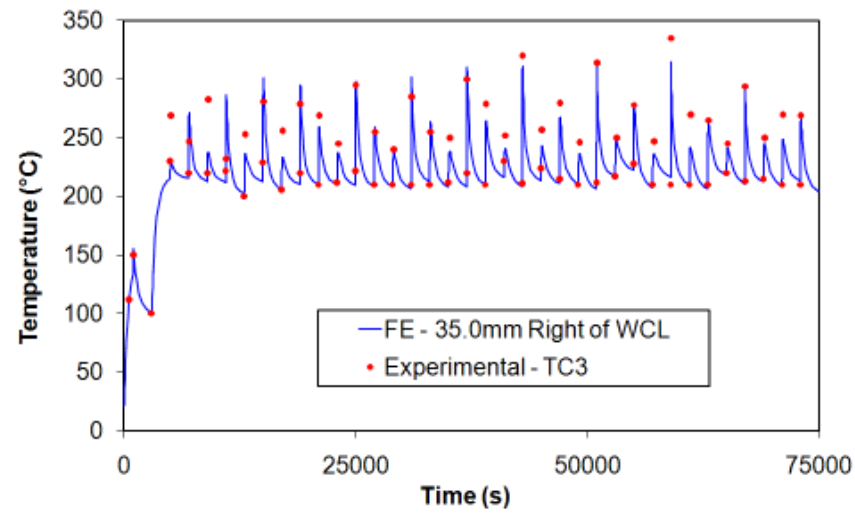

Figure 12. Temperature measurements by TC 3 and FE temperature history.

worth noting, however, that the welding procedure took place over a period of four days, throughout which the interpass temperature was maintained and recorded. The figures also show that the FE interpass temperatures, i.e. the minimum FE cyclic temperatures, vary from one pass to the other. This has been effected in the FE simulation by changing the sink temperature, associated with the electric blanket, in each step (i.e. for each pass) in the input file, in order to achieve better agreement with the experimental results.

\subsection{Temperature history of the FE model}

The thermal cycles due to welding induce metallurgical changes in the weld region and HAZ, which lead to the final microstructure of the welded pipe, which is significant since it is desired that the pipe has good resistance to creep and fracture under the abrasive conditions during service. Usually, the HAZ is the most vulnerable part of the pipe, risking the accumulation of creep damage at the intercritical zone, near the edge of the HAZ where the peak temperature is $830^{\circ} \mathrm{C}$ (which is the $\mathrm{Ac}_{1}$ of the $\mathrm{P} 92$ steel, at which austenitic transformation starts), and eventually leading to

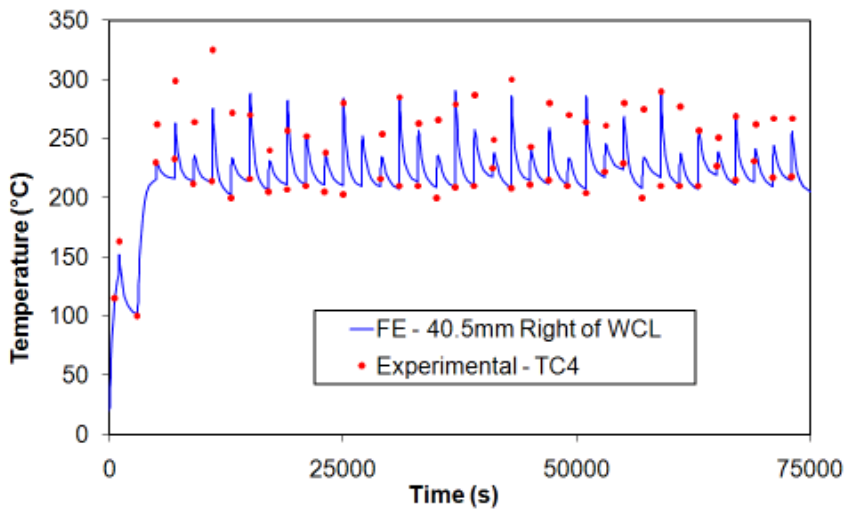

Figure 13. Temperature measurements by TC4 and FE temperature history.

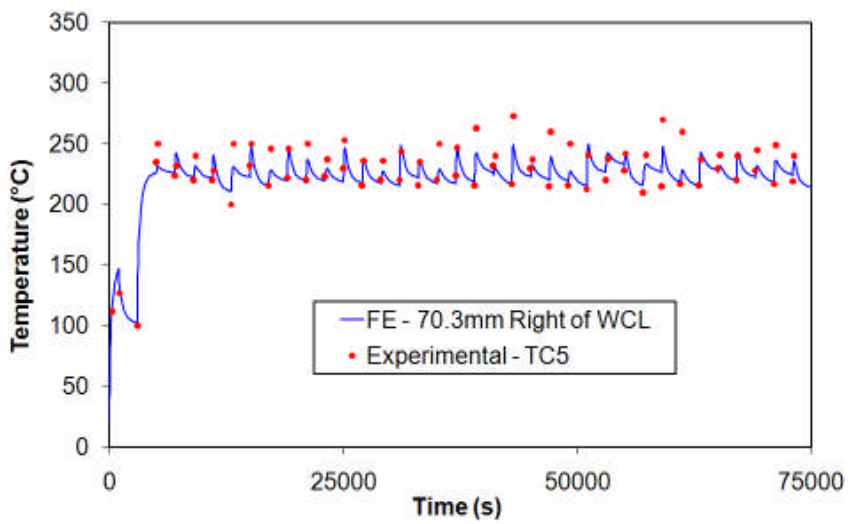

Figure 14. Temperature measurements by TC5 and FE temperature history.

creep failure in the same region. Therefore it is useful to identify the peak temperatures throughout the FE model, to try to relate them to any mechanical features, such as residual stresses or microstructurally-distinct regions in the weld material or HAZ. For that reason, the peak temperatures for the FE model have been identified and plotted in Fig. 15 in the form of contours. It can be seen from the figure that the peak temperature in some of the weld passes can exceed $2000^{\circ} \mathrm{C}$. This has not been verified experimentally, so until then, it would be difficult to establish whether it is typical of welding or whether it is peculiar to the way the heat fluxes are prescribed in the FE simulation. Peak temperatures, however, in the fusion welding of such materials, as the ones reported here, are expected to be hundreds of degrees higher than the melting point of the materials involved. The peak temperatures in the FE thermal analysis can be obtained by running a simple User Defined Field (USDFLD) subroutine together with the input file. The subroutine can keep a record of the peak temperatures by equating a State Field Variable in the subroutine to the temperature whenever the latter is on the rise. The State Field Variable can then be plotted from the 


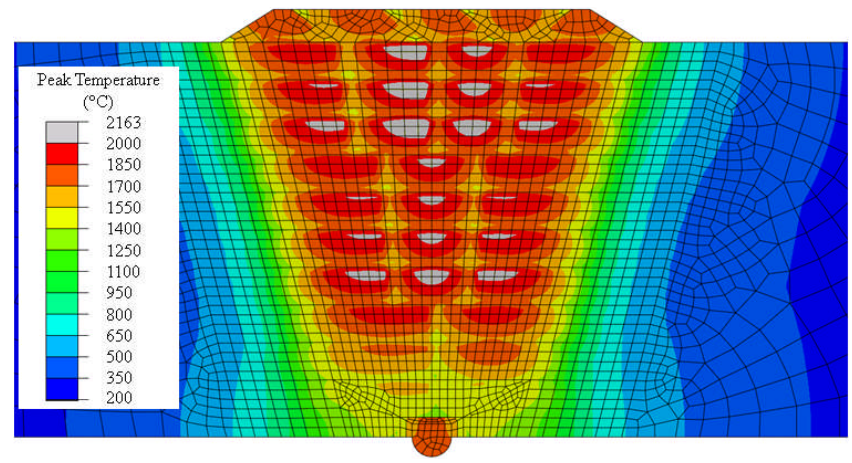

Figure 15. Peak temperature contours.

results file as the peak temperature throughout the process of welding.

Certain areas of interest have been plotted in Fig. 16 using the same FE peak temperature results. Referring to the solidus and liquidus temperatures of the P92, IN82 and IN625, four distinct regions in the FE model have been identified and plotted in Fig. 16: fully-melted zone, partiallymelted zone, $\mathrm{HAZ}$, and pipe region always below $830^{\circ} \mathrm{C}$ (which is the $\mathrm{Ac}_{1}$ of the P92 steel). It can be seen that the pipe material has experienced full or partial melting wherever it comes into contact with the weld material and that the HAZ, away from the pipe bore, is typically around $3 \mathrm{~mm}$ in width.

\section{Discussion and concluding remarks}

The FE thermal analysis of a dissimilar welded pipe has been presented. The pipe is made of P92 steel and the weld is made of IN82 for the first weld pass and IN625 for the other 35 passes. Residual stresses induced by the welding thermal cycles can be detrimental to the mechanical integrity of the pipes and their performance in service, and therefore they will be the subject of a future paper by the authors, determined by performing an FE sequentially-coupled structural analysis, based on the reported thermal analysis, using the same FE mesh, comprising 2919 axisymmetric (2-D) elements and 9022 nodes. The total number of increments in the thermal analysis was 5856 and the total number of iterations was 16887 . The run-time (wallclock time in the Abaqus message file) was almost one hour, using Microsoft Windows XP Professional $\times 64$ Edition operating system and a computer (PC) having Intel Core i5-660 (dual $3.33 \mathrm{GHz}$ processor cores) and $7.86 \mathrm{~GB} 1066 \mathrm{MHz}$ RAM.

The elements of the weld as well as the pipe have been created as part of the FE mesh right from the start. The weld elements are rendered inactive at the beginning and they are in turn activated to simulate their deposition. The step in the input file in which each weld pass is activated must be separate from the subsequent step prescribing the heat flux associated with the pass deposition. This is necessary because in Abaqus any heat flux prescribed during the activation of elements

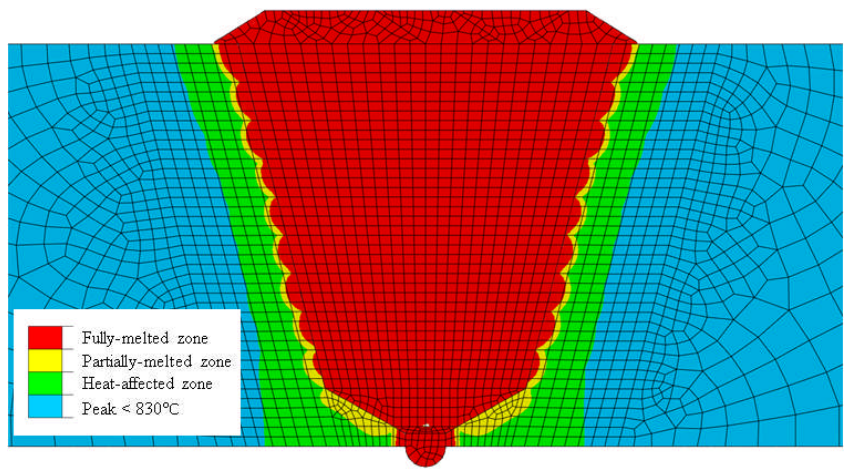

Figure 16. Fusion and thermal zones.

within the same step would be linearly ramped up from zero to the prescribed magnitude over the step time, which would completely jeopardise the heat flux. Therefore, keeping the activation of the weld elements and the prescription of the heat fluxes in separate steps in the input file is essential for a thermally correct simulation. Another numerical consideration which is worth noting is that the weld elements become thermally active when they are activated during the thermal analysis. If they were significantly different in temperature from the surrounding elements, they would act as a heat sink and would disrupt the temperature history in the region. To avoid this from happening, it has been necessary to revisit the input file and adjust the initial temperature prescribed to all the weld elements, so that when they are activated, they match the temperature of the surrounding elements. For that purpose, initial temperatures of $20^{\circ} \mathrm{C}$ and $210^{\circ} \mathrm{C}$ have been finally assigned to the pipe and weld elements, respectively.

The FE thermal analysis of welding requires the adjustment of the heat flux associated with the deposition of each weld pass to obtain the expected molten zones throughout the pipe thickness. Extensive parametric analyses by the authors have indicated that when the material thermal properties used in the FE simulation are slightly changed, the heat fluxes have to be adjusted to maintain the size and shape of the molten zones, cancelling out the effect of changing the value of the properties. This explains why the temperature history obtained at the weld region and HAZ can still be accurate when approximate thermal material properties are used in the FE thermal analysis. This argument applies only to the thermal part of the simulation. The structural analysis part has to have accurate material property data, otherwise the accuracy of residual stresses becomes compromised.

The results from the FE thermal analysis have been validated by comparing them to experimentally measured temperatures at five locations on the outer surface of the pipe. Although the FE simulation is axisymmetric, it still provides a temperature history which is considered to be sufficiently accurate for the purpose. Peak temperature contours, which determine fusion zones and the HAZ, have been obtained through a user defined subroutine and depicted for the FE model. 
Acknowledgements. We would like to acknowledge the support of The Energy Programme, which is a Research Councils UK cross council initiative led by EPSRC and contributed to by ESRC, NERC, BBSRC and STFC, and specifically the Supergen initiative (Grants GR/S86334/01 and EP/F029748) and the following companies; Alstom Power Ltd., Doosan Babcock, E.ON, National Physical Laboratory, Praxair Surface Technologies Ltd, QinetiQ, Rolls-Royce plc, RWE npower, Siemens Industrial Turbomachinery Ltd. and Tata Steel, for their valuable contributions to the project.

Edited by: A. Barari

Reviewed by: D. S. Simandjuntak and another anonymous referee

\section{References}

ABAQUS User Manual: version 6.9, Dassault Systèmes Simulia Corp., Providence, RI, USA, 2009.

Brickstad, B. and Josefson, B. L.: A parametric study of residual stresses in multi-pass butt-welded stainless steel pipes, Int. J. Pres. Ves. Pip., 75, 11-25, 1998.

Brózda, J.: New Generation Creep-Resistant Steels, their Weldability and Properties of Welded Joints: T/P92 Steel, Welding International, 19, 5-13, 2005.

Deng, D. and Murakawa, H.: Prediction of welding residual stress in multi-pass butt-welded modified 9Cr-1Mo steel pipe considering phase transformation effects, Comp. Mater. Sci., 37, 209-219, 2006.
Holloway, G. B., Zhang, Z., and Marshall, A. W.: Weld metals for USC power plant: Properties of T/P92 CrMo weld metals for ultra super critical (USC) power plant, Metrode Products Ltd, UK, August 2008.

Richardot, D., Vaillant, J. C., Arbab, A., and Bendick, W.: The T92/P92 Book, Vallourec \& Mannesmann tubes, 2000.

Saunders, N., Superalloys, R., Kissinger, R. D., Deye, D. J., Anton, D. L., Cetel, A. D., Nathal, M. V., Pollock, T. M., and Woodford, D. A. (Eds.): TMS, Warrendale, PA, 115 pp., 1996.

Special Metals: Inconel Alloy 625, Publication Number SMC-063, January 2006.

The Engineering ToolBox: Metals and Latent Heat of Fusion, available at: www.engineeringtoolbox.com/ fusion-heat-metals-d_1266.html, cited on 31 January 2011.

Yaghi, A. H., Hyde, T. H., Becker, A. A., Williams, J. A., and Sun, W.: Residual stress simulation in welded sections of P91 pipes, J. Mater. Process. Tech., 167, 480-487, 2005.

Yaghi, A. H., Hyde, T. H., Becker, A. A., Sun, W., Hilson, G., Simandjuntak, S., Flewitt, P. E. J., Pavier, M. J., and Smith, D. J.: A comparison between measured and modelled residual stresses in a circumferentially butt-welded P91 steel pipe, J. Press. Vess.T. ASME, 132, 011206-1-011206-10, 2010. 